\title{
Fragmentation and Kinetic Energy Release of Ions Produced from $\mathrm{C}_{2} \mathrm{H}_{5} \mathrm{OH}$
}

\author{
E. Szot*, K. GŁuCh And L. WÓJCIK \\ Department of Molecular Physics, Institute of Physics, Maria Curie-Skłodowska University \\ pl. Marii Curie-Skłodowskiej 1, 20-031 Lublin, Poland
}

\begin{abstract}
The high resolution double focusing mass spectrometer of reversed Nier-Johnson geometry was used in research of ionization and fragmentation processes of ethanol molecules $\mathrm{C}_{2} \mathrm{H}_{5} \mathrm{OH}$. Using the mass-analyzed ion kinetic energy technique, fragmentation paths and kinetic energy release distributions were examined for the four fragmentation reactions: $\mathrm{C}_{2} \mathrm{H}_{6} \mathrm{O}^{+} \rightarrow \mathrm{C}_{2} \mathrm{H}_{5} \mathrm{O}^{+}, \mathrm{C}_{2} \mathrm{H}_{6} \mathrm{O}^{+} \rightarrow \mathrm{C}_{2} \mathrm{H}_{3} \mathrm{O}^{+}, \mathrm{CH}_{3} \mathrm{O}^{+} \rightarrow \mathrm{CH}_{2} \mathrm{O}^{+}$and $\mathrm{CH}_{3} \mathrm{O}^{+} \rightarrow \mathrm{CHO}^{+}$. For all fragment ions from these reactions mean values of kinetic energy release $\langle\varepsilon\rangle$ were determined. We calculated mean values of $\langle\varepsilon\rangle$ as $22.70 \mathrm{meV}, 62.15 \mathrm{meV}, 30.25 \mathrm{meV}$, and $117.20 \mathrm{meV}$ for $\mathrm{C}_{2} \mathrm{H}_{5} \mathrm{O}^{+}, \mathrm{C}_{2} \mathrm{H}_{3} \mathrm{O}^{+}, \mathrm{CH}_{2} \mathrm{O}^{+}$, and for $\mathrm{CHO}^{+}$ions, respectively.
\end{abstract}

DOI: $10.12693 /$ APhysPolA.123.797

PACS: 07.75.+h, 34.80.Ht, 33.15.Fm, 34.80.Gs

\section{Introduction}

Ethanol as one of the most popular solvents, is widely used in chemical industry, where it is a component of fuels [1], founds, paints, lacquers or perfumes. Due to its flavor properties and simple production process (i.e. fermentation of sugar), ethanol is applied in the food industry. In medicine it is used for disinfection and sterilization.

Due to the above applications, a number of $\mathrm{C}_{2} \mathrm{H}_{5} \mathrm{OH}$ molecules, ions and free radicals is present in the atmosphere where they can undergo ion-molecule and fragmentation reactions. We can study these processes in laboratory conditions and observe how molecules and their fragments decline in the ionosphere, as a result of decay processes of the parent ions.

Ions and free radicals of $\mathrm{C}_{2} \mathrm{H}_{5} \mathrm{OH}$ can interact with each other. As a final result there is possibility of the formation of particular ions and compounds causing greenhouse effect. For this reason it is useful to determine the behavior of ions under conditions ionization and fragmentation processes of $\mathrm{C}_{2} \mathrm{H}_{5} \mathrm{OH}$ can occur.

Pilling et al. measured dissociation channels of double ionized ethanol [2] employing soft X-ray photons from a toroidal grating monochromator beamline and time-of-flight mass spectrometer TOF-MS. They obtained mean kinetic energies, abundances and dissociation pathways.

In our earlier studies we examined ionization and fragmentation processes of acrylonitrile, acetaldehyde and methanol [3-6]. In the experiment reported here, we obtained fragmentation pathways for single ionized ions, created as a result of collision of the electron beam with the molecules of ethanol $\left(\mathrm{C}_{2} \mathrm{H}_{5} \mathrm{OH}\right)$. Moreover, we assessed the values of mean kinetic energies of fragmented

*corresponding author; e-mail: ewelina.szot@gmail.com ions created as a result of spontaneous fragmentation of parent ions.

\section{Experimental}

Using the double focusing mass spectrometer of the Nier-Johnson (B-E) geometry allows us to obtain basic information about ionization processes, recorded mass spectrum of primary ions, and assessed appearance energies. Moreover, we can use the mass-analyzed ion kinetic energy (MIKE) technique for the parent and fragmented ions. On the basis of the MIKE spectra, we can determine decay channels of the ionized molecule, the life time of fragmenting ions as well as kinetic energy release and kinetic energy release distributions for the fragmented ions [3-7]. This spectrometer was described in detail previously, and in this work it is described briefly $[3-5,8]$. The apparatus contains the Nier-type electron impact ion source and the channeltron-type based detection system. The vacuum system allows to obtain the background pressure of $4 \times 10^{-8} \mathrm{mbar}$ in the measurement system.

The vapor of heated ethanol (purity $98 \%$ ) is introduced into the ionization chamber in the ion source through a capillary leak gas inlet system. In that chamber the electrons of approximately $100 \mathrm{eV}$ energy, colliding with $\mathrm{C}_{2} \mathrm{H}_{6} \mathrm{O}$ molecules produce ions. Electrons are emitted from the heated cathode and focused into a beam by the magnetic field parallel to the electron beam axis. During measurements the electron current was constant and was set to $0.3 \mathrm{~mA}$. The ions created in the ion source are extracted from the ionization chamber by a weak electric field. Ions are formed into a beam and accelerated to the required energy by the system of electrodes with appropriately selected potentials. For the present results the accelerating voltage $\left(U_{\text {acc }}\right)$ was set to $4 \mathrm{kV}$. Afterwards the focused and accelerated ion beam is deflected by the $90^{\circ}$ magnetic field, where the ions are separated 
due to their momentum. Then the ion fragments pass through the second field-free region $(f f 2)$ and again they are deflected by the $90^{\circ}$ electric field. Finally, the ion beam is registered in the detection system by using the channeltron-type electron multiplier [3-5].

\section{Theoretical interpretation of MIKE spectra}

The used MIKE technique gives the possibility to observe and interpret spontaneous fragmentation of the parent ions $\left(z_{\mathrm{p}}, m_{\mathrm{p}}\right)$ into the fragment ions $\left(z_{\mathrm{f}}, m_{\mathrm{f}}\right)$, which are created in the second field-free region $(f f 2)$. It also gives the opportunity to get information about the kinetic energy carried by the fragment ions, as well as the mutual sharing of energy between the fragments, during the fragmentation process $[3,4]$.

MIKE spectra are recorded by tuning the magnet to transmit only the parent ions and changing the value of the electric sector voltage. The electric sector transmits fragment ions $\left(z_{\mathrm{f}}, m_{\mathrm{f}}\right)$ if the sector voltage for fragment ions $\left(U_{\mathrm{f}}\right)$ is set to the following condition:

$$
U_{\mathrm{f}}=\frac{m_{\mathrm{f}} z_{\mathrm{p}}}{m_{\mathrm{p}} z_{\mathrm{f}}} U_{\mathrm{p}}
$$

where $U_{\mathrm{p}}$ is the voltage between the electrodes of the electric field sector for the observed maximum of the parent ions signal and $U_{\mathrm{f}}$ is the voltage for fragment ion, respectively.

During the measurements reported here, the observed MIKE peaks have the Gaussian shape. In this case the analysis of MIKE spectra and calculation of $\left\langle\varepsilon_{\mathrm{MIKE}}\right\rangle$ are relatively simple [7]. When the peaks shapes are slightly different, the complex methods of analysis must be used. The mean kinetic energy carried by ions, that are created as a result of fragmentation processes occurring in the $f f 2$ sector, can be calculated from formula (2), based on the width at half maximum of the Gaussian approximation of the MIKE spectra for the fragment ions $[9,10]$ :

$$
\left\langle\varepsilon_{\mathrm{MIKE}}\right\rangle=2.16 \frac{z_{\mathrm{f}}^{2}\left(m_{\mathrm{p}}\right)^{2} U_{\mathrm{acc}}}{16 z_{\mathrm{p}}\left(m_{\mathrm{f}}\right)\left(m_{\mathrm{p}}-m_{\mathrm{f}}\right)}\left(\frac{\Delta U}{U_{\mathrm{p}}}\right)^{2},
$$

where $\Delta U$ is the width at half maximum (FWHM) of the MIKE peak of the fragment ions, formed during the fragmentation of the parent ion.

The value of the kinetic energy release can be also obtained by using kinetic energy release distributions (KERDs) [11]. Based on the definition of mean value, the average kinetic energy $\left\langle\varepsilon_{\mathrm{KER}}\right\rangle$, obtained from the KER diagrams, is defined as the "center of gravity" below the graph of KERD.

\section{Results and discussion}

Figure 1 presents the mass-ion spectrum of ethanol. The most intensive peak belongs to the ion $\mathrm{CH}_{3} \mathrm{O}^{+}$, although the molecular ion is $\mathrm{C}_{2} \mathrm{H}_{6} \mathrm{O}^{+}$. Very low intensity of the molecular peak observed in the mass spectrum, confirms the rapid disintegration into the fragments occurring directly in the ion source.

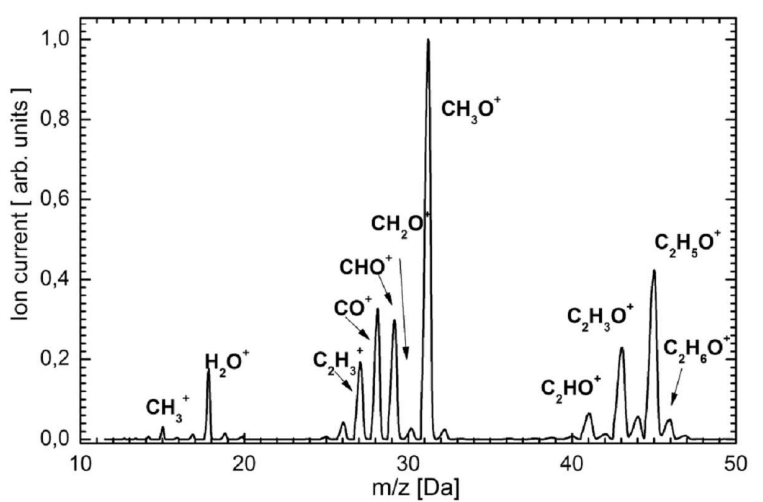

Fig. 1. The mass spectrum of the primary ions of $\mathrm{C}_{2} \mathrm{H}_{5} \mathrm{OH}$.

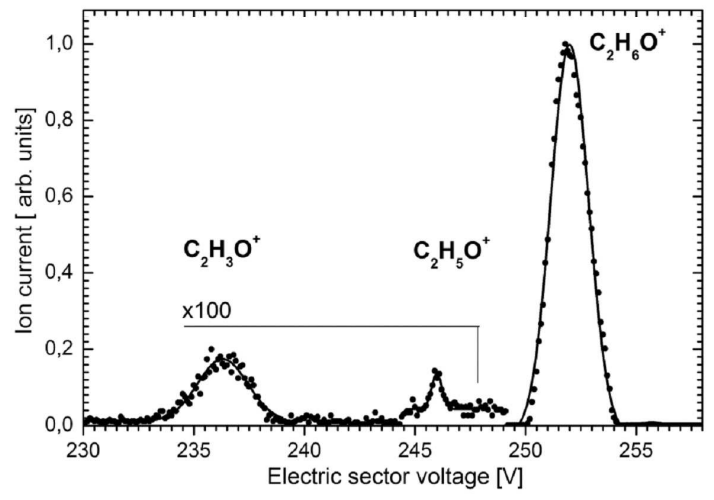

Fig. 2. The MIKE spectrum for the parent ions $\mathrm{C}_{2} \mathrm{H}_{6} \mathrm{O}^{+}$and their fragments: $\mathrm{C}_{2} \mathrm{H}_{5} \mathrm{O}^{+}$and $\mathrm{C}_{2} \mathrm{H}_{3} \mathrm{O}^{+}$.

We observed four fragmentation reactions occurring in the $f f 2$ region, see below Eqs. (3)-(6). For all these reactions the MIKE spectra were obtained and they are presented in Figs. 2 and 3. First two fragmentations are the decay of the molecular ions $\mathrm{C}_{2} \mathrm{H}_{6} \mathrm{O}^{+} \rightarrow \mathrm{C}_{2} \mathrm{H}_{5} \mathrm{O}^{+}$and $\mathrm{C}_{2} \mathrm{H}_{6} \mathrm{O}^{+} \rightarrow \mathrm{C}_{2} \mathrm{H}_{3} \mathrm{O}^{+}$with the loss of one or three hy-

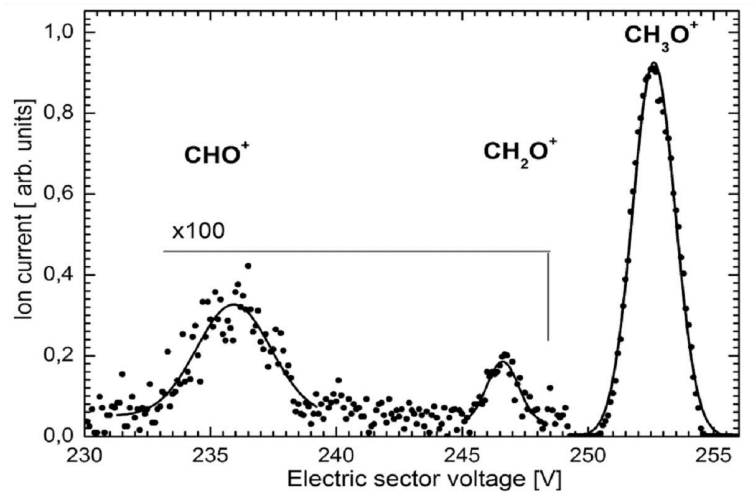

Fig. 3. The MIKE spectrum for the parent ions $\mathrm{CH}_{3} \mathrm{O}^{+}$and their fragments: $\mathrm{CH}_{2} \mathrm{O}^{+}$and $\mathrm{CHO}^{+}$. 
drogen atoms, respectively. The other two processes are fragmentations of the parent ions $\mathrm{CH}_{3} \mathrm{O}^{+}$into two fragments $\mathrm{CH}_{2} \mathrm{O}^{+}$and $\mathrm{CHO}^{+}$:

$$
\begin{aligned}
& \mathrm{C}_{2} \mathrm{H}_{6} \mathrm{O}^{+} \rightarrow \mathrm{C}_{2} \mathrm{H}_{5} \mathrm{O}^{+}+\mathrm{H}, \\
& \mathrm{C}_{2} \mathrm{H}_{6} \mathrm{O}^{+} \rightarrow \mathrm{C}_{2} \mathrm{H}_{3} \mathrm{O}^{+}+3 \mathrm{H}, \\
& \mathrm{CH}_{3} \mathrm{O}^{+} \rightarrow \mathrm{CH}_{2} \mathrm{O}^{+}+\mathrm{H}, \\
& \mathrm{CH}_{3} \mathrm{O}^{+} \rightarrow \mathrm{CHO}^{+}+2 \mathrm{H} .
\end{aligned}
$$

For these reactions, the kinetic energies of the fragment ions were calculated by using Eq. (2). The values of $\left\langle\varepsilon_{\mathrm{MIKE}}\right\rangle$ energies, determined from this formula are presented in Table.

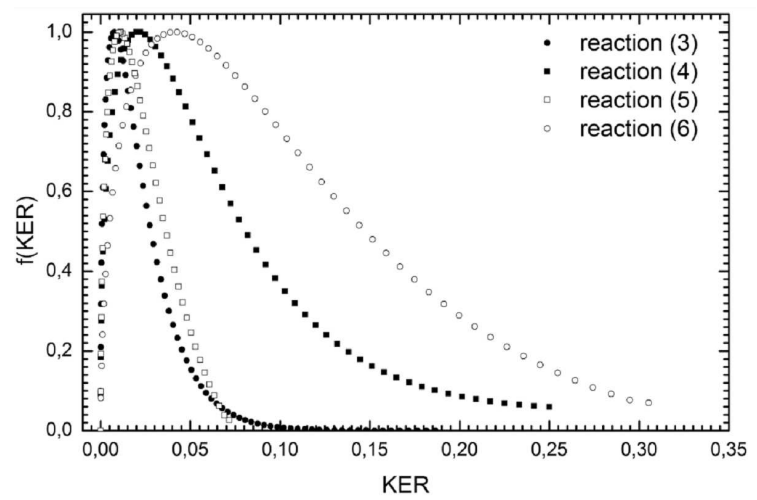

Fig. 4. The kinetic energy release distributions for the ions $\mathrm{C}_{2} \mathrm{H}_{5} \mathrm{O}^{+}, \mathrm{C}_{2} \mathrm{H}_{3} \mathrm{O}^{+}, \mathrm{CH}_{2} \mathrm{O}^{+}$and $\mathrm{CHO}^{+}$created as a result of fragmentation reactions (3)-(6).

TABLE

The values of mean kinetic energy release $\langle\varepsilon\rangle$.

\begin{tabular}{c|c|c}
\hline \hline \multirow{2}{*}{ Reaction } & \multicolumn{2}{|c}{ Values of $\langle\varepsilon\rangle[\mathrm{meV}]$} \\
\cline { 2 - 3 } & $\left\langle\varepsilon_{\mathrm{MIKE}}\right\rangle$ & $\left\langle\varepsilon_{\mathrm{KER}}\right\rangle$ \\
\hline$(3)$ & 22.6 & 22.8 \\
$(4)$ & 62.7 & 61.6 \\
$(5)$ & 33.6 & 26.9 \\
$(6)$ & 125.4 & 109.0
\end{tabular}

For all the observed fragmented ions, also KERDs were obtained [7, 11], and they are presented in Fig. 4. In order to compare energies $\left\langle\varepsilon_{\mathrm{KER}}\right\rangle$ assessed on the basis of the KER diagrams, the results are also presented in Table. It is worth mentioning that the $\left\langle\varepsilon_{\mathrm{MIKE}}\right\rangle$ values obtained directly from formula (2) and the energies determined from the KER diagrams $\left\langle\varepsilon_{\mathrm{KER}}\right\rangle$ are almost the same.

\section{Conclusions}

We studied ionization and fragmentation processes, induced by collisions of the electron beam with the molecules of ethanol $\mathrm{C}_{2} \mathrm{H}_{6} \mathrm{O}$.
On the basis of MIKE spectra, fragmentation decay channels for two metastable parent ions: $\mathrm{C}_{2} \mathrm{H}_{6} \mathrm{O}^{+}$and $\mathrm{CH}_{3} \mathrm{O}^{+}$, which were created inside the ion source as a result of the electron beam ionization, were determined. The four fragmentation reactions were examined (reactions from Eqs. (3)-(6)). For these fragmentations the mean values of the kinetic energy release $\langle\varepsilon\rangle$ for the four fragmented ions: $\mathrm{C}_{2} \mathrm{H}_{5} \mathrm{O}^{+}, \mathrm{C}_{2} \mathrm{H}_{3} \mathrm{O}^{+}, \mathrm{CH}_{2} \mathrm{O}^{+}$and $\mathrm{CHO}^{+}$were received using two methods. These energies were calculated to: $22.70 \mathrm{meV}$ for $\mathrm{C}_{2} \mathrm{H}_{5} \mathrm{O}^{+}$ions, that were created as a result of fragmentation reaction (3), $62.15 \mathrm{meV}$ for $\mathrm{C}_{2} \mathrm{H}_{3} \mathrm{O}^{+}$ions, $30.25 \mathrm{meV}$ for $\mathrm{CH}_{2} \mathrm{O}^{+}$ions, and $117.20 \mathrm{meV}$ for $\mathrm{CHO}^{+}$ions. As far as we are concerned the KERDs were obtained for the first time for the single-ionized ions of this molecule.

In the earlier studies we have calculated appearance energies and values of $\langle\varepsilon\rangle$ for example for acrylonitrile or methanol $[3-6,8]$. The results of those studies were consistent with the literature, which testifies to the advantages and accuracy of all our measurements.

\section{References}

[1] C. Park, Y. Choi, C. Kim, O. Seungmook, G. Lim, Y. Moriyoshi, Fuel 89, 2118 (2010).

[2] S. Pilling, H.M. Boechat-Roberty, A.C.F. Santos, G.G.B. de Souza, J. Electron Spectrosc. Relat. Phenom. 155, 70 (2007).

[3] K. Głuch, E. Szot, A. Gruszecka, M. SzymańskaChargot, J. Cytawa, L. Michalak, Vacuum 83, S20 (2009).

[4] E. Szot, L. Wójcik, K. Głuch, Vacuum 90, 141 (2013).

[5] K. Głuch, J. Cytawa, L. Michalak, Int. J. Mass Spectrom. 273, 20 (2008).

[6] E. Szot, L. Wójcik, K. Głuch, Elektronika 8, 63 (2011).

[7] K. Głuch, S. Matt-Leubner, O. Echt, P. Scheier, T.D. Mark, Vacuum 81, 1129 (2007).

[8] K. Głuch, J. Cytawa, L. Michalak, Int. J. Mass Spectrom. 278, 10 (2008).

[9] R.G. Cooks, J.H. Beynon, R.M. Caprioli, G.R. Lester, Metastable Ions, Elsevier, Amsterdam 1973, Ch. 4.

[10] K. Głuch, J. Fedor, S. Matt-Leubner, O. Echt, A. Stamatovic, M. Probst, J. Chem. Phys. 118, 3090 (2003).

[11] K. Głuch, S. Matt-Leubner, O. Echt, R. Deng, J.U. Andersen, P. Scheier, T.D. Mark, Chem. Phys. Lett. 385, 449 (2004). 